\title{
Performance Testing of Hydraulic Cements: Measuring Sulfate Resistance
}

\author{
Chiara F. Ferraris, Paul E. Stutzman, and Max Peltz \\ National Institute of Standards and Technology, \\ Gaithersburg, MD 20899, USA \\ Chiara.ferraris@nist.gov \\ Paul.stutzman@nist.gov \\ Max.peltz@nist.gov
}

\begin{abstract}
The sulfate resistance of cements used in the construction industry is traditionally assessed by measuring the expansion of a prism of $280 \mathrm{~mm}$ (11inch) length and $25 \mathrm{~mm}$ (1 inch) square cross section immersed in a sodium sulfate solution for at least one year. The duration of the experiment limits this test from being used as a performance-based determination of innovative mixtures of cementitious materials. In response to the need for a more rapid test protocol, the National Institute of Standards and Technology (NIST) has developed a new test method that measures the expansion of smaller bars (10 mm x $10 \mathrm{~mm}$ x $60 \mathrm{~mm}$ ) made with neat cement paste. With these bars, similar expansion is achieved in less than 3 months, reducing the test duration by a factor of at least 4 . This accelerated test method provides more rapid results consistent with the traditional test procedure, allowing for a shorter decision time and the screening of more materials.
\end{abstract}

Key words: degradation; expansion measurements; hydraulic cement; sulfate attack; sulfate resistance.

Accepted: May 21, 2018

Published: May 25, 2018; Current Version: April 22, 2019

https://doi.org/10.6028/jres.123.010

\section{Introduction and Background}

Concretes with portland cement or blended hydraulic cement binders are susceptible to external sulfate-induced degradation. The sulfate ions interact with sulfoaluminates and portlandite hydration products of cements causing a volume increase and softening of the hardened cement matrix. This problem tends to be more prevalent in arid regions where soil sulfate contents are higher, in areas with sulfatecontaining waters and ground waters, and in sanitary wastewater handling systems where sulfate-reducing bacteria can degrade concrete. Cements have been traditionally tested for sulfate resistance using ASTM C1012 [1] where the length change of a mortar prism immersed in a sodium sulfate solution is monitored over time. While this test provides a good measure of relative performance, the procedure can take between 6 months to 18 months. This limits the utility of the test procedure for screening new cements and evaluating new components of hydraulic blended cements, cements containing some proportion of fly ash, slag, or silica fume.

Concrete structures exposed to sulfates emanating from soils or water are prone to degradation, as a result of the sulfate ion reactions with hydration products in the cementitious binder. As stated above, to assess the resistance of a concrete exposed to sulfate, the construction industry relies upon a performancebased test method, ASTM C1012 [1]. This test measures expansion of a specimen immersed in a sulfate solution (typically sodium sulfate), requiring measurements for up to 18 months. Test specimens are three prisms $(25.4 \mathrm{~mm} \times 25.4 \mathrm{~mm} \times 279.4 \mathrm{~mm})$ of mortar with a special pin cast in both ends of the specimen to 
facilitate measurement of changes in length. The specimens are cured in limewater until they achieve a strength of $20 \mathrm{MPa}$, after which they are then placed in the sodium sulfate solution to begin the test. The change in length is monitored at designated test times using a frame and a comparator. The cement is considered sulfate resistant if the expansion does not exceed a pre-selected value, most often $0.1 \%$, after (6 to 18 ) months. Ferraris et al. [7, 8] conducted a study to develop a new test method that could provide test results consistent with ASTM C1012 in a fraction of the time. Validation testing demonstrates a reduction in testing time by a factor of three to five, depending upon the materials combinations. This is the test presented here using small specimens of $10 \mathrm{~mm}$ x $10 \mathrm{~mm}$ x $60 \mathrm{~mm}$. The specimen mold configuration and the final methodology was refined after the initial development in collaboration with Prof. Doug Hooton and his student Mila Aleksic [9]. This tutorial presents the refined method. This method was presented to ASTM for standardization, but it has not yet been adopted.

NIST conducted tests to determine a preliminary uncertainty of the small-specimen test [unpublished data]. A test result is defined as the mean of results for a set of at least four individual specimens, preferably six. The uncertainty for length change from a test result from one laboratory and one operator, calculated as one standard deviation has been found to be $0.11 \%$ before onset of deterioration and $0.25 \%$ post-deterioration (defined as an expansion in excess of $0.1 \%$ ). Therefore, using the $95 \%$ repeatability limits (d2s) following ASTM practice, a single operator working within one laboratory should obtain expansions for the same cement that differ by no more than $0.25 \%$. No multi-laboratory standard deviation (reproducibility) is available at this time.

A new test has been developed at NIST to determine the susceptibility of a hardened cement paste specimen to react with external sulfate by measuring its expansion. This test is applicable to portland cements, blends of portland cement with pozzolans or slags, and blended hydraulic cements. Results of this test method are consistent with those obtained using ASTM C 1012 [1] but are typically obtained three to five times faster than in C1012 due to the use of neat cement paste and a smaller specimen size. The following is the complete test protocol.

\subsection{Audience}

This test is designed to be used by a cement manufacturer, testing laboratory, or concrete mix designer who is concerned with the impact of sulfate attack on a concrete. It is intended for usage in a laboratory setting and not in the field.

\subsection{Education or Skill Level}

To use this test method, the operator should be familiar with normal physical testing procedures used in cement or concrete laboratories. An experienced technician would be able to follow the instructions provided here.

\section{Materials and Equipment}

\subsection{Materials}

The following materials are required to conduct the test. The material being tested, i.e., cement, is not included in this list.

The water should be reagent-grade water conforming to Type IV of ASTM Specification D 1193 [2].

Saturated limewater solution is prepared using calcium hydroxide $(4 \mathrm{~g} / \mathrm{L})$ in water. Excess of calcium hydroxide should be visible at the bottom after vigorous stirring. 
The test exposes the specimen prepared (see section 2) to a $5 \%$ (mass fraction) sodium sulfate $\left(\mathrm{Na}_{2} \mathrm{SO}_{4}\right.$ ) aqueous solution with a pH between 6.0 and 8.0. The sodium sulfate shall be reagent grade, conforming to the specifications of the Committee on Analytical Reagents for the American Chemical Society. The solution does not need to be prepared daily, so depending on the size of the container, prepare several liters at the same time. The procedure is provided here to prepare $1 \mathrm{~L}$ :

- The water content of the sodium sulfate to be used shall be determined by loss on ignition or thermogravimetric analysis (TGA) each time the solution is prepared. Any source of anhydrous or hydrated sodium sulfate may be used if the water content of the sodium sulfate is determined by testing and proper corrections made to account for the specified sulfate concentration.

- "Each liter of solution shall contain $50.0 \mathrm{~g} \pm 0.5 \mathrm{~g}$ of $\mathrm{Na}_{2} \mathrm{SO}_{4}$ dissolved in $900 \mathrm{~mL} \pm 5 \mathrm{~mL}$ of water, and shall be diluted with additional distilled or deionized water to obtain $1.0 \mathrm{~L}$ solution" (section 5.4 of ASTM C1012 [1]) at $23^{\circ} \mathrm{C} \pm 2{ }^{\circ} \mathrm{C}$. (Uncertainties here and throughout represent one standard deviation.)

- Prepare the solution at least one day before use, place in a tightly closed container, and store it at $23{ }^{\circ} \mathrm{C} \pm 2{ }^{\circ} \mathrm{C}$.

- Determine the $\mathrm{pH}$ of the solution before use; reject the solution if the $\mathrm{pH}$ range is outside of the 6.0 to 8.0 range. A pH meter is convenient for this determination.

Epoxy to protect the ends of the specimens - To ensure that the penetration of the sodium sulfate primarily occurs along the long sides of the specimens, their ends need to be protected by using an epoxy. Any type of epoxy that adheres to the wet surface of a hardened cement paste specimen and does not dissolve or debond (peel off) in a sodium sulfate solution would be suitable. For instance, a two-part adhesive that is suitable for binding metals-glass-ceramics-plastics- wood-rubber-fabrics-concrete with low water absorption has been found to be suitable ${ }^{1,2}$. Suitable epoxies should be able to cure at room temperature in about $20 \mathrm{~min}$ and be fully cured in less than $24 \mathrm{~h}$ (see section 2 under Curing the specimen).

\subsection{Equipment Needed}

The equipment needed to conduct the test includes devices usually found in a cement testing laboratory: a balance, graduated cylinders, spatulas, and spoons to prepare the cement paste. Balances shall conform to ASTM Specification C 1005 [3].

To prepare the paste, a mixer that conform to ASTM C1738 [4] is recommended. This is a high-shear blender with $1 \mathrm{~L}$ capacity. The equipment needed for casting and length-change measurements includes the following: specially designed molds, a reference bar, rod, and special tips to adapt an ASTM C1012 [1] length-change comparator, containers to store the specimens, plastic bags, and a temperature-controlled environmental chamber or room. Each item is described below.

The molds are specifically designed for this test and shall conform to the design shown in Fig. 1. A list of parts is provided in Table 1. The prisms obtained from these molds will be $10 \mathrm{~mm}$ x $10 \mathrm{~mm}$ x $60 \mathrm{~mm}$ with studs embedded at both ends. For the molds shown in Fig. 1, the tolerance on internal dimensions is $\pm 0.2 \mathrm{~mm}$. The parts of the molds shall be tight fitting and hold firmly together when assembled, and their surfaces shall be smooth and free of pits to comply with digital tolerances. The mold shall be made of

\footnotetext{
${ }^{1}$ Epoxy 907 from Miller-Stephenson has performed adequately.

${ }^{2}$ Certain commercial products are identified in this paper to specify the materials used and procedures employed. In no case does such identification imply endorsement or recommendation by the National Institute of Standards and Technology, nor does it indicate that the products are necessarily the best available for the purpose.
} 
a material that will allow easy demolding without the use of demolding agents or oils. Suitable materials include polyvinyl chloride (PVC Type II), rigid high-density polyethylene (HDPE), Nylon (type 35 6/12), Deldrin $^{\odot} 3$ Acetal resin, or polytetrafluoroethylene (PTFE). Each clamp (Fig. 1/Table 1 - item \#2) of the mold shall be equipped to hold the gauge studs embedded in the specimen properly in place (Fig. 1) during the setting period. Some more details on specific parts are as follows:

- $\quad$ The threaded studs (Fig. 1/Table 1 item \#8) are $12.7 \mathrm{~mm}$ [1/2 in] in length and of the type M3x0.5 [4/40 thread]. They should be made of type 316 stainless steel (American Iron and Steel Institute (AISI)) or another corrosion-resistant metal of similar hardness. The threaded studs shall be set so that their principal axes coincide with the principal axis of the test specimen.

- Positioning screws (Fig. 1/Table 1 - item \#6) and the mold blocks (Fig. 1/Table 1- item \#4) shall hold in place the gauge studs during sample preparation and initial curing.

The reference gauge, used to zero the length comparator, is made of Invar metal and has the shape shown in Fig. 2. The dimensions are: length of $75.0 \mathrm{~mm} \pm 0.2 \mathrm{~mm}$ [2.950 in $\pm 0.008 \mathrm{in}$ ] and diameter of $17.0 \mathrm{~mm} \pm 0.2 \mathrm{~mm}[0.700 \mathrm{in} \pm 0.008 \mathrm{in}]$. The top and bottom pins are $2.7 \mathrm{~mm} \pm 0.2 \mathrm{~mm}[0.106 \mathrm{in} \pm 0.008$ in] in diameter and $7 \mathrm{~mm} \pm 0.2 \mathrm{~mm}$ [0.276 in $\pm 0.008 \mathrm{in}]$ in length.

The length comparator must conform to the requirements of ASTM Specification C490 [5] with modifications to accommodate the smaller specimens. One method to accommodate small specimens is to add a rod as shown in Fig. 3, made of the same material as the stand and of suitable length to accommodate measurement of the specimens. The diameter of the rod shown as an example in Fig. 3 is $25 \mathrm{~mm}$ [1 in] and the length from the stand base is $248 \mathrm{~mm}$ [9.7 in]. The bottom of the rod needs to be able to be attached to the base. Usually a threaded rod of suitable diameter and a bolt under the base would suffice. Tips that are screwed at the top of the rod and at the end of the axis of the micrometer (Fig. 3) are shown in Fig. 4. These are specially designed to be used with the threaded studs (Fig. 1/Table 1, item \#8).

A container for sulfate solution in which the bars are immersed shall be of any material that does not react with the sodium sulfate solution. The container shall include a tight-fitting lid to prevent evaporation of the sulfate solution. A plastic food container large enough to hold the bars horizontally on two nonreactive rods to keep them positioned slightly off the bottom to allow for solution circulation would be satisfactory. The rods may be constructed of the same materials as that used to construct the molds.

A container for curing the epoxy after it is applied to the specimen could be a pan covered with plastic wrap or aluminum foil and a small amount of water in the bottom to keep the specimens from drying. The pan should contain supports to elevate the specimens, to keep epoxy on the bar sides from adhering and the entire specimen above the water in the bottom of the pan. This curing container could be a duplicate of the container for the sulfate solution, provided the rods do not touch the portion of the specimen ends coated with epoxy.

A chamber or cabinet is needed for storing the specimens for the duration of the test. It should be capable to maintain the temperature at $23^{\circ} \mathrm{C} \pm 2{ }^{\circ} \mathrm{C}$ or, with the same precision, other temperatures if desired.

Plastic bags are used to store the molds with the fresh specimen during the curing process in the first $24 \mathrm{~h}$. Thus, they should be large enough to contain one mold and should be sealable. A large re-sealable freezer bag that could hold one mold was found to be suitable. 


\section{Journal of Research of the National Institute of Standards and Technology}

Table 1. Parts list for construction of the specimen molds illustrated in Fig. 1. The non-SI units were used to facilitate the purchase of the parts.

\begin{tabular}{|c|c|c|c|}
\hline Item no. & Part number & Description & Quantity \\
\hline 1 & Mold base & & 1 \\
\hline 2 & Mold clamp & Hold mold spacers in place & 2 \\
\hline 3 & Mold spacers & Separate the specimens & 7 \\
\hline 4 & Mold blocks & Holds the gauges in the specimens & 12 \\
\hline 5 & $\begin{array}{l}\text { 18-8 Stainless steel hex drive flathead } \\
\text { screw (8-32 thread size, } 3 / 4 \text { in long) }\end{array}$ & Screws that attach the clamps to the base & 6 \\
\hline 6 & $\begin{array}{l}\text { Positioning screws (18-8 stainless steel } \\
\text { socket head screw (8-32 thread size, } 1.5 \text { in } \\
\text { long) - modified shown in part } 6 \text { in Fig. } 1 .\end{array}$ & Holds the mold blocks in place & 12 \\
\hline 7 & $\begin{array}{l}\text { 18-8 Stainless steel hex nut (8-32 Thread } \\
\text { size) }\end{array}$ & $\begin{array}{l}\text { Nuts to be used with item } 5 \text { to secure the } \\
\text { clamps to the base }\end{array}$ & 6 \\
\hline 8 & $\begin{array}{l}\text { Threaded studs: } 12.7 \mathrm{~mm}(1 / 2 \text { in) length - } \\
4 / 40 \text { thread. }\end{array}$ & $\begin{array}{l}\text { Threaded studs used as gauge (part will be in } \\
\text { the specimen and part will be sticking out to } \\
\text { measure expansion) }\end{array}$ & 12 \\
\hline
\end{tabular}

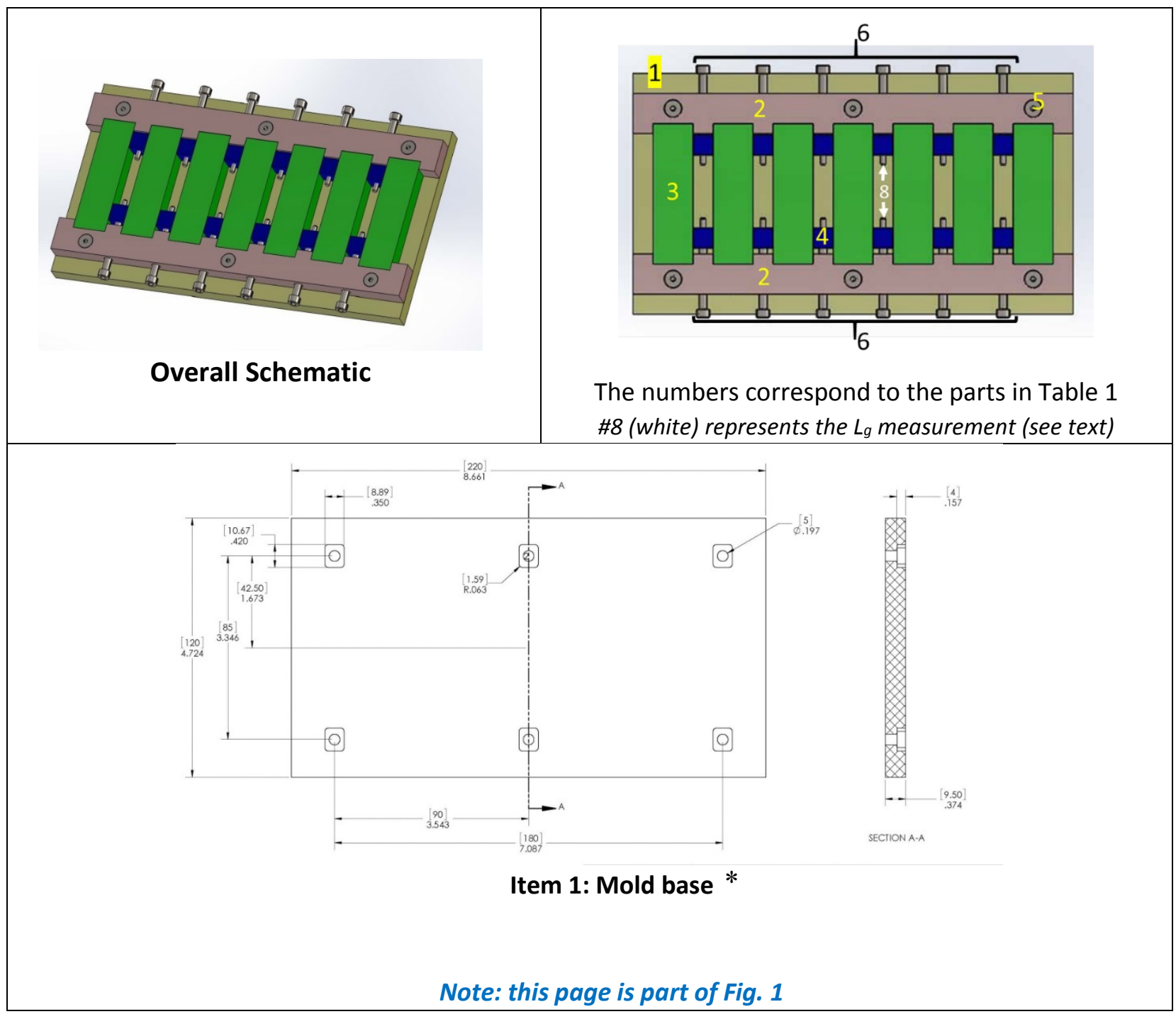

*Dimensions corrected on April 22, 2019: For item 1, mold base, the width should be $140 \mathrm{~mm}$ (5.512 in) instead of $120 \mathrm{~mm}$ (4.724 in); the distance between the holes should be $105 \mathrm{~mm}$ (4.134 in) instead of $85 \mathrm{~mm}$ (3.346 in). 


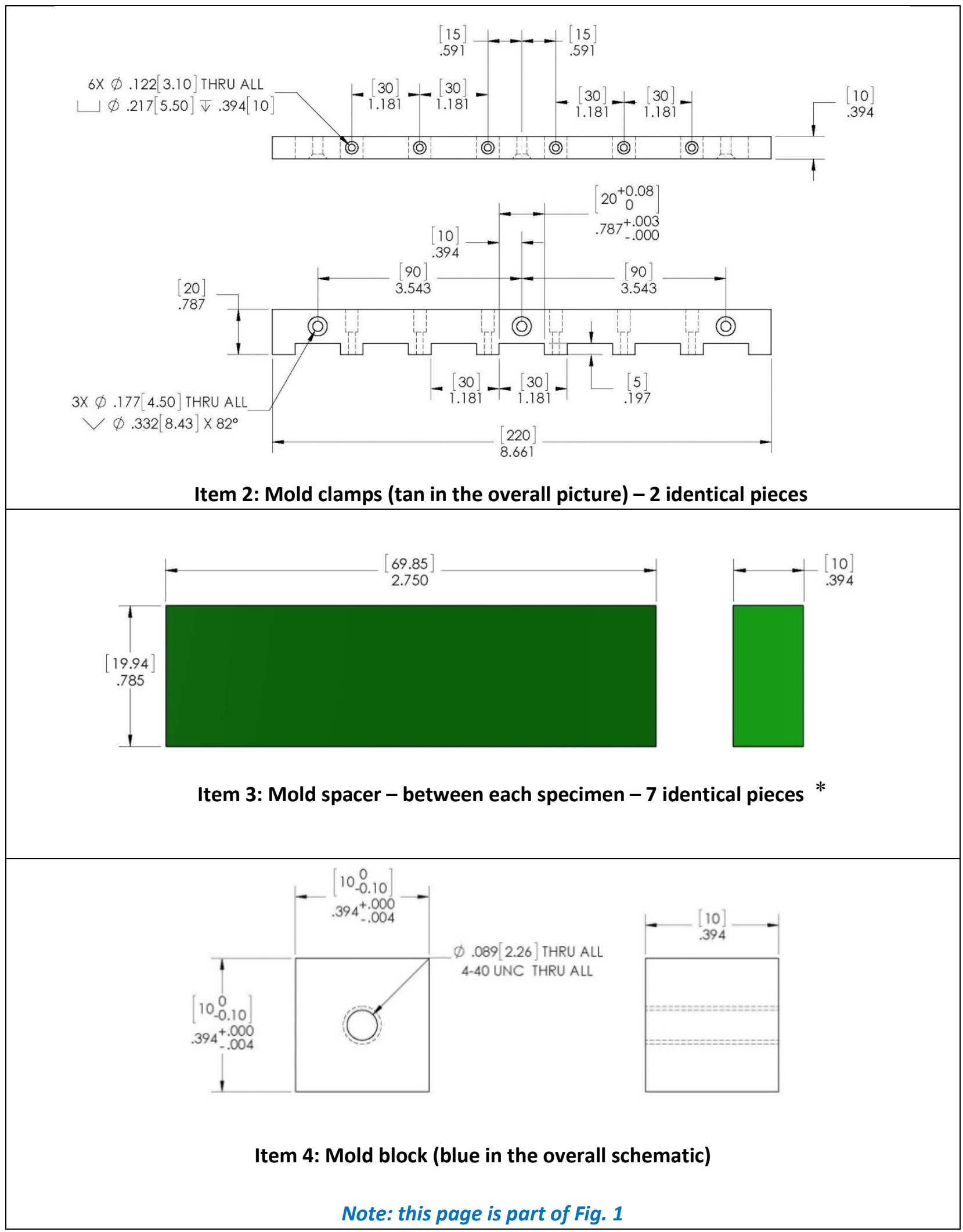

*Dimensions corrected on April 22, 2019: For item 3, mold spacer, the length should be $90 \mathrm{~mm}$ (3.543 in) instead of $69.85 \mathrm{~mm}$ (2.750 in). 


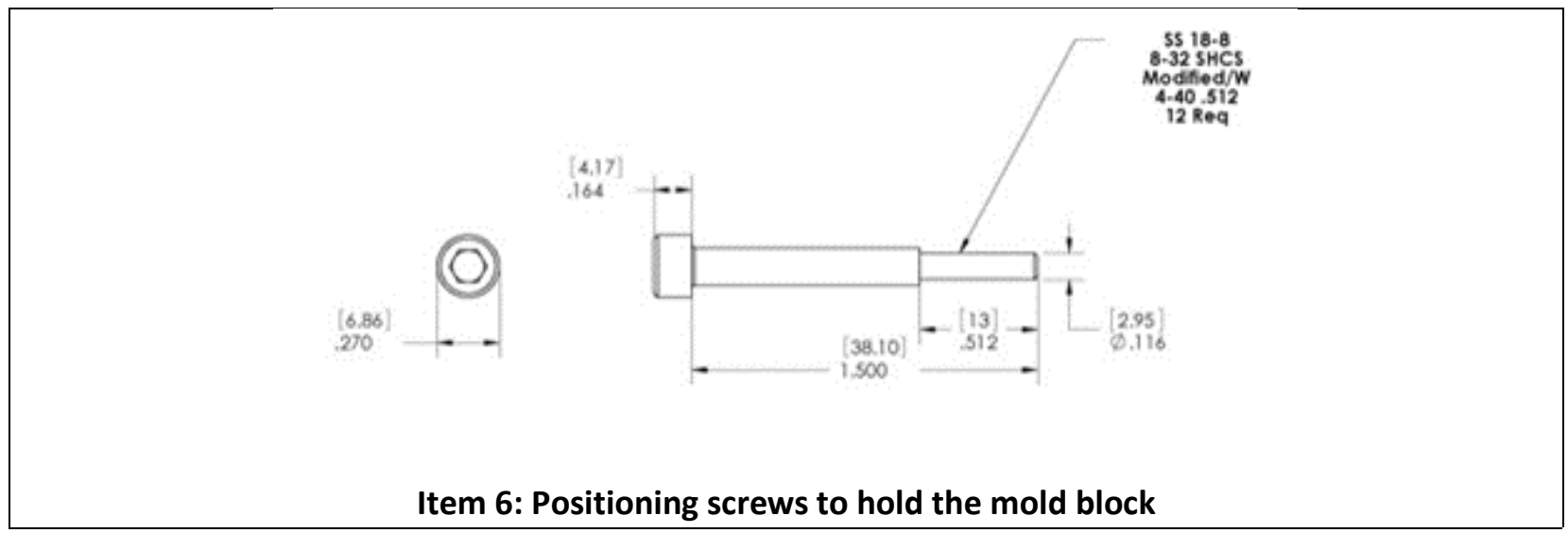

Fig. 1. Design drawing of the molds. The units are customary, inches, with the metric units, millimeters, in brackets. The molds could be built metric while using customary screws (\# 5, 7, and 8 on the list) or vice versa. Item numbers correspond to Table 1.

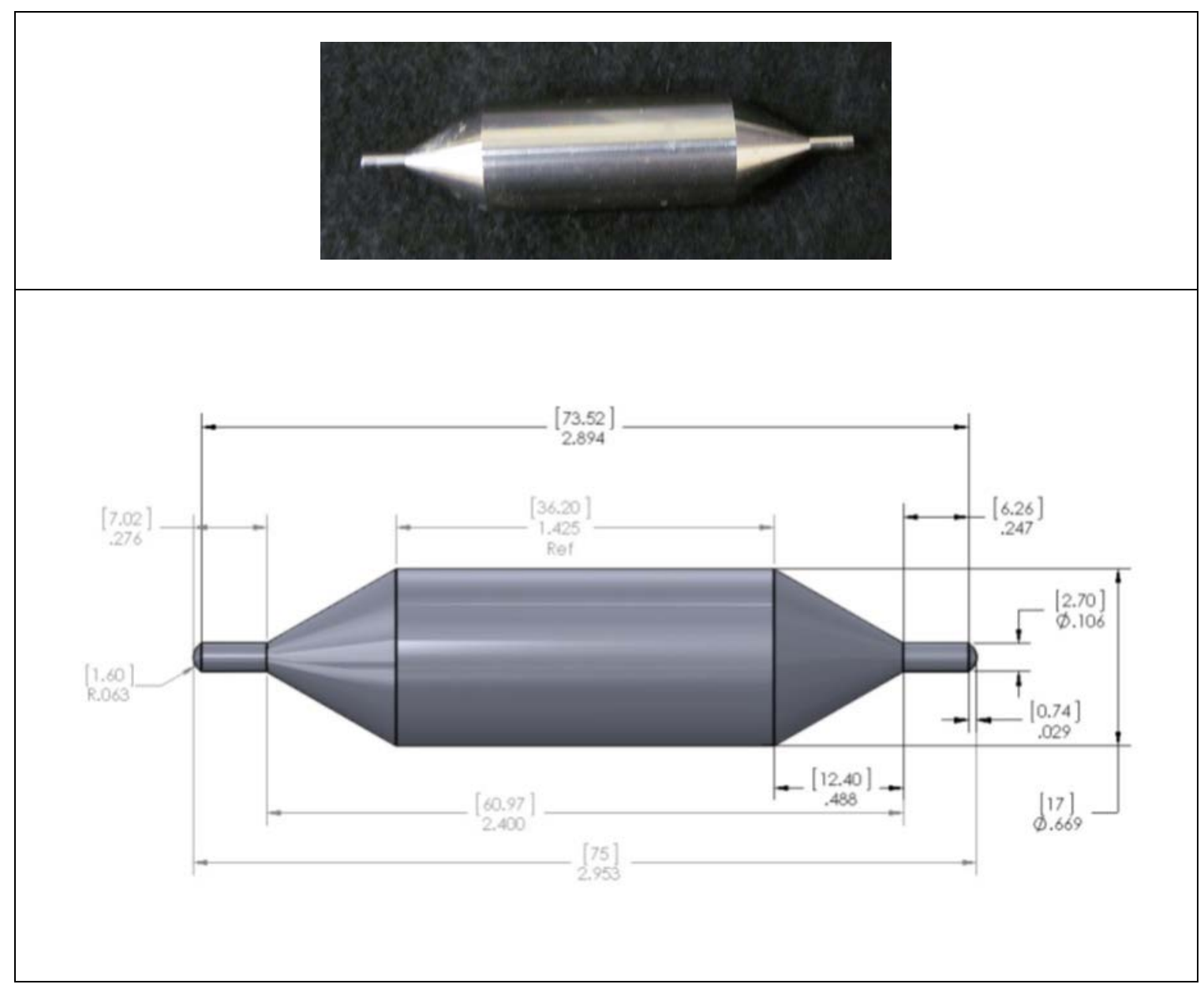

Fig. 2. Reference bar with customary units of inches, with the SI units (mm) in brackets. 


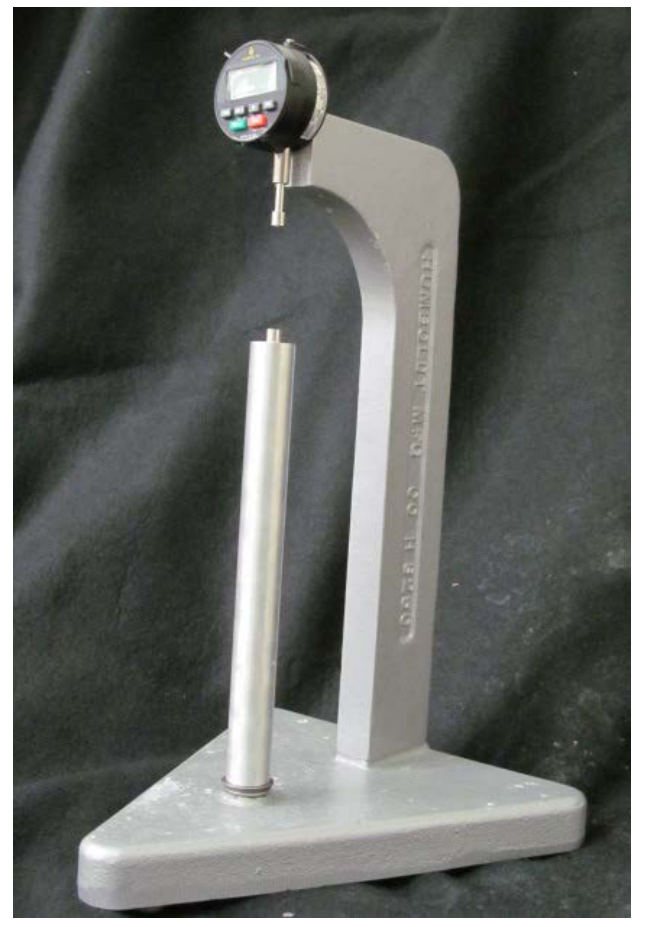

Fig. 3. Spacer rod used to accommodate smaller specimens using the same stand as for C1012.

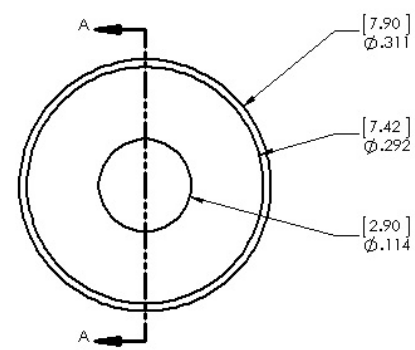

$\begin{aligned} {[X . X X] } & =\text { Metric } \\ X X X & =\text { Inch }\end{aligned}$

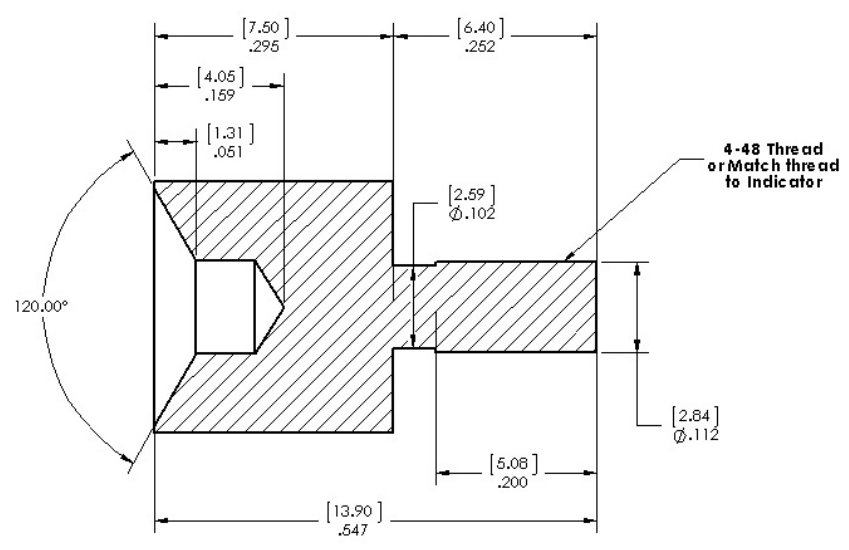

SECTIONA-A
SCALE $8: 1$

Fig. 4. Tips to be used with the comparator. The units are customary, inches, with the SI units, millimeters, in brackets. 


\subsection{Safety Considerations}

Fresh hydraulic cementitious mixtures are caustic and may cause chemical burns to skin and tissue upon prolonged exposure ${ }^{3}$. Proper protective equipment including nitrile gloves and safety glasses should be used when handling materials.

\section{Procedure}

The first step is to assemble the mold:

- Lay out the clamps (Fig. 1/Table 1, item 2) on the base (Fig. 1/Table 1 item \#1), aligning the holes in the base with the holes in the clamps.

- Position the spacers (Fig. 1/Table 1, Item \#3) between the clamps as shown in Fig. 1.

- Place the screws (Fig. 1/Table 1, Item \#5) and secure the clamps to the base using the nuts (Fig. 1/Table 1, Item 7). Ensure that the spacers are well aligned and secured.

- Screw a stud halfway (Fig. 1/Table 1, item \#8) into each of the 12 blocks (Fig. 1/Table 1, item 4). Use some grease such as a thin film of petroleum jelly on the part of studs' threads that will be in the blocks before inserting them into the blocks. Ensure that no petroleum jelly is on the portion of the stud that will be within the specimen.

- Place all 12 blocks (Fig. 1/Table 1, Item \#4) as shown in Fig. 1, with the studs toward the inside of the specimen.

- Insert the positioning screws (Fig. 1/Table 1, item \#6) as shown in Fig. 1 to secure the blocks.

- Measure using a caliper the distance between the tips of the studs (Fig. 1, Item \#8). Precaution should be taken to ensure that the distance between the two tips of the studs is identical for all six specimens within $0.5 \mathrm{~mm}$ [0.02 in.]. Record the distance between the tips of the studs inside the molds and calculate an average. This average will be used as the base for the expansion calculation as the nominal length, $\mathrm{Lg}$ (see equation (1)). If the dimensions of the molds are as expected, $\mathrm{Lg}$ should be approximately $27.7 \mathrm{~mm}$ [1.1 in].

Modify the comparator stand by inserting the spacer rod on the base after removing the pin support that is normally there. Then, insert on top of the rod the tip (Fig. 4). Replace the tip attached to the comparator (see Fig. 3) with another tip (Fig. 4).

Calculate the correct amounts of material to be prepared at the desired water content. It is best to use the same cement paste mixture for all six specimens in one mold, as four to six specimens per set have been found to be appropriate for determining precision and some might break during demolding. For example, it was found that $54.0 \mathrm{~g}$ of cementitious material and a water amount of $24.3 \mathrm{~g}$, corresponding to a water/cementitious material ratio of 0.45 , was adequate to fill molds for six specimens $\left(36 \mathrm{~cm}^{3}\right)$. Quantities required depend on the density of the cement tested (as it contains materials other than portland cement).

Prepare the cement paste to be tested. It is recommended to mix the paste following the procedures described in ASTM C1738, but other methods may be acceptable. Note that this ASTM procedure requires about $300 \mathrm{~g}$ of cement to ensure proper blending of the materials.

Fill the mold with the cement paste, using a spoon to pour the material in each space and compact by tapping the side of the mold to eliminate entrapped air. Ensure that the cement paste encases the studs embedded in the specimens. Level the top surface with a spatula and minimize the paste smeared on top of the spacers. After the mold is filled, place it in a plastic bag with $1 \mathrm{~mL}$ to $2 \mathrm{~mL}$ of water to maintain $100 \%$ relative humidity (RH). Tightly close bags ensuring that the bag does not touch the top surface of the paste (leave air in it). Figure 5 illustrates how it can be done, by pinching the bag while closing it tightly. Then store the bag with the mold for $24 \mathrm{~h}$ in a curing cabinet or chamber at a constant temperature of $23.0^{\circ} \mathrm{C} \pm$ $2.0^{\circ} \mathrm{C}$. This constitutes the initial curing phase.

\footnotetext{
${ }^{3}$ See Manual of Cement Testing, Section on Safety, Annual Book of ASTM Standards, Vol. 04.01.
} 


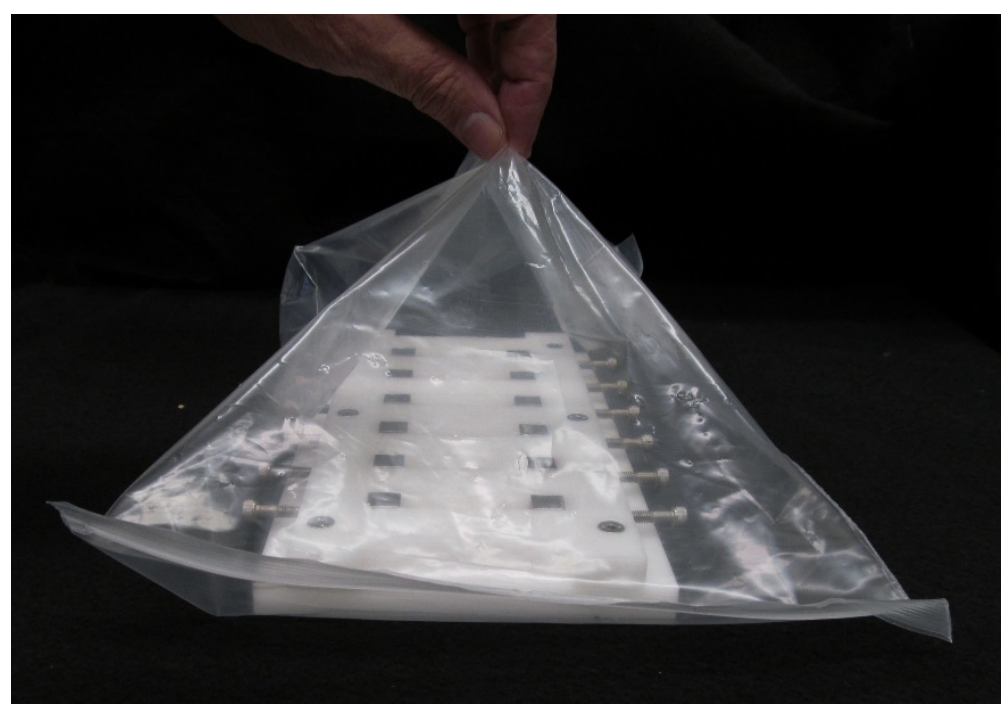

Fig. 5. Curing bag set-up.

Demold using the following technique to minimize damaging the specimens:

- Remove the 12 positioning screws on both sides on the mold. (Fig. 1/Table 1, Item \#6)

- Keeping the mold flat on the bench, remove the 6 screws (Fig. 1/Table 1, Item \#5) holding the two clamps (Fig. 1/Table 1, Item \#2). Do not remove the base and do not lift the top assembly. The two clamps should be loose.

- Use the handle of a screw driver or your fingers to tap lightly on the mold spacer blocks (Fig. 1/Table 1 , item \#3 in green) to separate specimens from mold pieces. The goal is to separate the specimens from the spacers without lifting the specimens. This will reduce breakage in the specimen.

- Use a putty knife to scrape off any paste that has formed on the block (Fig. 1/Table1, Item \#4).

- Gently pick up one specimen and hold it on two sides with fingers close to the block (Fig. 1/Table1, Item \#4) and twist off the block gently. Repeat with the other side of the specimen and then with each additional specimen.

Cure the specimens by storing them with saturated limewater solution at $23.0^{\circ} \mathrm{C} \pm 2.0^{\circ} \mathrm{C}$ for $3 \mathrm{~d}$.

After the $3 \mathrm{~d}$ curing period, remove the specimens from the limewater and apply epoxy to protect the pinends of the specimen (Fig. 6):

- Use a towel to blot excess surface water from the specimen.

- Apply epoxy to both end surfaces of the specimen. Avoid smearing epoxy on the studs but ensure that epoxy seals the region where the stud enters the specimen. The epoxy should cover the first $5 \mathrm{~mm}$ along the sides of the specimen to minimize sulfate penetration from the ends. Figure 6 shows the ideal application of the epoxy.

- $\quad$ Cure the epoxy by placing the specimens in a covered container (plastic wrap or aluminum foil). The container should have rods to support the specimens above water placed in the container bottom to maintain an atmosphere of $100 \% \mathrm{RH}$. Keep the specimen undisturbed for between $5 \mathrm{~h}$ and $6 \mathrm{~h}$. This will prevent the specimens from drying during the epoxy cure. Do not allow water to contact the specimens or the epoxy during this curing.

- Label each specimen with a letter or number (writing on the specimen with an indelible marker should be adequate).

- Return the specimens to the limewater until the start of exposure to sulfate solution, usually $7 \mathrm{~d}$ after casting. 
Obtain the initial specimen lengths. Use the comparator in accordance with ASTM Specification C490 [5]. Use the reference gauge to ensure that the comparator is zeroed. Have the container with the sulfate solution standing by. Mark one face of each specimen with an arrow to ensure that the specimen orientation is kept constant for all readings.

Extract a specimen from the limewater, blot it dry, and measure its length by placing it in the comparator, rotating it 6.28 rad $\left(360^{\circ}\right)$ over the long axis, aligning with the arrow, and recording the reading. It is recommended to make several initial measurements, by rotating the specimen in the comparator, to ensure that the value is stable (variation less than $0.001 \mathrm{~mm}$ ). These measurements are considered the initial specimen length. Record the date and time of measurements.

Repeat the process with all six specimens. After reading the last specimen, clean the hole in the comparator base and check that the reference gauge indication is still zero. If the reference gauge does not read zero plus/minus the resolution of the comparator of $0.001 \mathrm{~mm}$, repeat all specimen measurements after first again zeroing the comparator with the reference gauge.

Immerse the specimens in the sodium sulfate solution. After the measurements are made and all data are recorded, place the specimens in the sulfate solution. Then place the container with the specimens in the sodium sulfate solution in a chamber at $23.0^{\circ} \mathrm{C} \pm 2.0^{\circ} \mathrm{C}$ or other desired temperature

Monitor the length change due to the exposure to the solution daily (at least 5 times per week) for the first 2 weeks and then once a week thereafter until deterioration commences.

- Measure and record the temperature of the solution.

- Ensure that the comparator is zeroed for each measurement time by using the reference gauge. Extract a specimen from the solution, blot it dry, and measure its length by placing it in the comparator, rotating it $360^{\circ}$, aligning with the arrow. Record the measurements and the exact time at which they were made (date and time). Note any cracking (presence, location, type) or surface deposition and exudations (nature, thickness, type).

- After reading the last specimen, clean the hole in the comparator base and check that the reference gauge indication is still zero. If the reference gauge does not read zero plus/minus the resolution of the comparator of $0.001 \mathrm{~mm}$, repeat all specimen measurements after first again zeroing the comparator with the reference gauge.

- After all the specimens in the container are measured, empty the sodium sulfate solution, rinse the container, refill with fresh sodium sulfate solution, and secure the container lid. Place the container back in the controlled temperature chamber. 


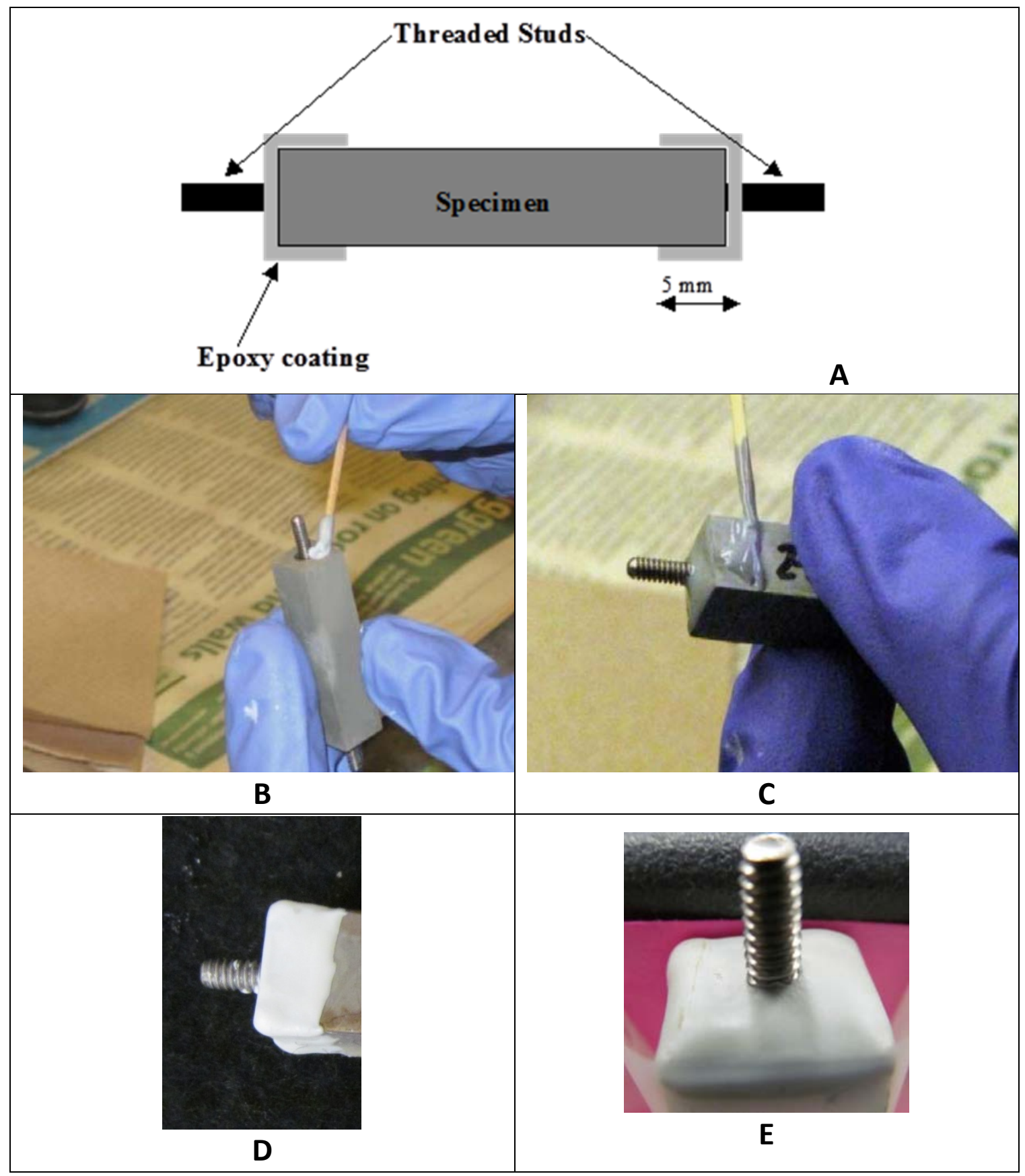

Fig. 6. Method to cover the ends of a specimen with epoxy. A) schematic on the location of the epoxy on the specimen; B) and C) show how to apply the epoxy; D) and E) show an example of a completed epoxy application. 
Calculation of the expansion of the specimen is done using the following equation (1):

$$
\Delta L=\frac{L_{x}-L_{i}}{L_{g}} \cdot 100
$$

where

$\Delta \mathrm{L}=$ Change in length at age $x, \%$ (also referred to as expansion)

$\mathrm{L}_{\mathrm{x}}=$ Comparator reading of specimen at age $x[\mathrm{~mm}]$

$\mathrm{L}_{\mathrm{i}}=$ Initial comparator reading of the specimen $[\mathrm{mm}]$

$\mathrm{L}_{\mathrm{g}}=$ The gauge length shall be considered as the nominal length $[\mathrm{mm}]$ as measured when the mold was constructed (Fig. 1, item \#8).

After the length is recorded from the comparator, the expansion for each bar is reported to the nearest 0.001 $\%$ and the average values are reported to the nearest $0.01 \%$, rounding according to Practice ASTM E 29 [10].

When reporting the results obtained using this test, provide the following information:

- Type and source of cement or combination of cementitious materials used and its composition,

- The cement paste composition, such as water content or water/cementitious materials ratio,

- A table containing the date and time of each measurement, the comparator readings measured for each of the six specimens (or at least four specimens if some broke during the demolding phase), the calculated expansion for each of the specimens, the average length change of the specimens, a standard deviation of the length change of the specimens,

- Any observations such as cracks or other deterioration signs,

- Any modification to this procedure (such as temperature).

\section{Acknowledgments}

The authors would like to thank Kenneth Snyder (NIST), Dale Bentz (NIST) and Gary Knight (Lehigh Hanson) for the thorough review of the paper. Also, our thanks go to Richard Eason (NIST) for performing the test for the first time using this tutorial and providing clarifying comments.

\section{Contact Information}

Chiara F. Ferraris, Group Leader of the Inorganic Materials Group in the Materials and Structural Systems Division at NIST, Chiara.ferraris@nist.gov.

\section{References}

[1] ASTM International (2018) ASTM C1012/C1012M-18a Standard Test Method for Length Change of Hydraulic-Cement Mortars Exposed to a Sulfate Solution (ASTM International, West Conshohocken, PA), https://doi.org/10.1520/C1012_C1012M-18A.

[2] ASTM International (2018) ASTM D1193-06(2018) Standard Specification for Reagent Water (ASTM International, West Conshohocken, PA), https://doi.org/10.1520/D1193-06R18.

[3] ASTM International (2017) ASTM C1005-17 Standard Specification for Reference Masses and Devices for Determining Mass and Volume for Use in the Physical Testing of Hydraulic Cements (ASTM International, West Conshohocken, PA). https://doi.org/10.1520/C1005-17.

[4] ASTM International (2018) ASTM C1738/C1738M-18 Standard Practice for High-Shear Mixing of Hydraulic Cement Pastes (ASTM International, West Conshohocken, PA), https://doi.org/10.1520/C1738_C1738M-18.

[5] ASTM International (2017) ASTM C490/C490M-17 Standard Practice for Use of Apparatus for the Determination of Length Change of Hardened Cement Paste, Mortar, and Concrete (ASTM International, West Conshohocken, PA), https://doi.org/10.1520/C0490_C0490M-17.

*Added on April 22, 2019: The authors also acknowledge John W. Hettenhouser for kindly preparing the drawings for Figs. 1, 2 and 4. 
[6] ASTM International (2013) ASTM C511-13 Standard Specification for Mixing Rooms, Moist Cabinets, Moist Rooms, and Water Storage Tanks Used in the Testing of Hydraulic Cements and Concretes (ASTM International, West Conshohocken, PA), https://doi.org/10.1520/C0511.

[7] Ferraris CF, Stutzman P, Snyder K, (2006) Sulfate Resistance of Concrete: a New Approach. Portland Cement Association (PCA), Skokie, Illinois, PCA R\&D Serial No. 2486. https://ciks.cbt.nist.gov/garbocz/monograph/SN248611.pdf

[8] Ferraris CF, Stutzman P, Peltz M, Winpigler J. (2005) Developing a More Rapid Test to Assess Sulfate Resistance of Hydraulic Cements. J Res Natl Inst Stan 110(5):529-540. https://doi.org/10.6028/jres.110.080.

[9] Aleksic M (2010) Development and Standardization of the NIST Rapid Sulfate Resistance Test. M.Sc. thesis. University of Toronto.

[10] ASTM International (2013) ASTM E29-13 Standard Practice for Using Significant Digits in Test Data to Determine Conformance with Specifications (ASTM International, West Conshohocken, PA), https://doi.org/10.1520/E0029.

\begin{abstract}
About the authors: Chiara F. Ferraris is the Group Leader in the Materials and Structural Systems Division of the Engineering Laboratory at NIST. Her present research focuses on rheological properties and development of SRMs for the construction industry.

Paul Stutzman is a Geologist in the Materials and Structural Systems Division of the Engineering Laboratory at NIST. His research focuses on characterization of concrete-making materials.

Max Peltz is a Technical Engineer in the Materials and Structural Systems Division of the Engineering Laboratory at NIST. His research focuses on testing and characterizing construction materials.

The National Institute of Standards and Technology (NIST) is an agency of the U.S. Department of Commerce.
\end{abstract}

